\title{
Fortified food consumption: impact on micronutrient adequacy and compliance with dietary recommendations in Irish children 1-4 years
}

\author{
Á. Hennessy, J. Walton and A. Flynn \\ School of Food and Nutritional Sciences, University College Cork, Cork, Republic of Ireland
}

Early childhood is a critical life stage in which optimum nutrient intakes are essential for healthy growth and development. The aim of this study was to evaluate the impact of fortified food (FF) consumption on the prevalence of inadequate micronutrient intake and on compliance with dietary recommendations for macronutrient intake in 500 Irish pre-school children aged 1-4 years. Analysis was based on the National Pre-School Nutrition Survey, which was carried out between 2010 and 2011, to establish a database of habitual food and drink consumption. A 4-day weighed food record was used to collect food intake data. Analysis of dietary intake data was carried out using WISP ${ }^{\odot}$ (Tinuviel Software, Anglesey, UK) which encompasses McCance and Widdowson's The Composition of Foods ${ }^{(1)}$, Sixth and Fifth editions (including supplemental volumes) and the Irish Food Composition Database ${ }^{(2)}$. On the basis of median daily energy intake from FFs, children were divided into low $(267 \mathrm{~kJ} / \mathrm{d})$, medium $(611 \mathrm{~kJ} / \mathrm{d})$ or high $(1181 \mathrm{~kJ} / \mathrm{d})$ consumers of FFs, (stratified by age). Underreporters were identified by an energy intake/basal metabolic rate ${ }^{(3)}$ ratio less than a defined cut-off point ${ }^{(4)}$ and were excluded from the analysis. Adequacy of micronutrient intake across thirds of FF consumption was evaluated against estimated average requirements $(\mathrm{EAR})^{(5,6)}$. In addition, compliance with European Food Safety Authority and UK Department of Health dietary recommendations for macronutrients ${ }^{(5,7,8)}$ was examined across thirds of FF consumption.

\begin{tabular}{|c|c|c|c|c|c|}
\hline Nutrient & EAR & Low $(n=119)$ & $\begin{array}{c}\text { Medium }(n=122) \\
\%<\text { EAR }\end{array}$ & High $(n=138)$ & $\chi^{2}$ \\
\hline Vitamin A & $300 \mu \mathrm{g} / \mathrm{d}$ & 15 & 14 & 11 & 0.578 \\
\hline \multirow[t]{3}{*}{ Vitamin D } & $10 \mu \mathrm{g} / \mathrm{d}$ & 98 & 97 & 86 & 0.000 \\
\hline & $<5 \mu \mathrm{g} / \mathrm{d}$ & 95 & 88 & 53 & 0.000 \\
\hline & $<1 \mu \mathrm{g} / \mathrm{d}$ & 27 & 21 & 8 & 0.000 \\
\hline \multirow[t]{2}{*}{ Iron } & $5.3 \mathrm{mg}$ ( $1-3$ years) & 24 & 9 & 2 & 0.000 \\
\hline & $4.7 \mathrm{mg}$ (4 years) & & & & \\
\hline Zinc & $\begin{array}{l}3.8 \mathrm{mg} \text { ( } 1-3 \text { years }) \\
5 \mathrm{mg} \text { (4 years) }\end{array}$ & 21 & 19 & 14 & 0.291 \\
\hline
\end{tabular}

\begin{tabular}{|c|c|c|c|c|c|}
\hline Macronutrient & Recommendation & $\begin{array}{c}\text { Low } \\
(n=119)\end{array}$ & $\begin{array}{c}\text { Medium } \\
(n=122) \\
\% \text { meeting recommendation }\end{array}$ & $\begin{array}{c}\text { High } \\
(n=138)\end{array}$ & $\chi^{2}$ \\
\hline Total Fat & $1-2 \mathrm{y}: \leqslant 40 \%$ TE; $3-4 \mathrm{y}: \leqslant 35 \%$ TE & 68 & 88 & 88 & 0.000 \\
\hline Saturated Fat & $\leqslant 11 \% \mathrm{TE}$ & 5 & 3 & 13 & 0.005 \\
\hline Carbohydrate & $\geqslant 50 \% \mathrm{TE}$ & 69 & 85 & 83 & 0.003 \\
\hline Dietary Fibre & $\geqslant 2 \mathrm{~g} / \mathrm{MJ} / \mathrm{day}$ & 69 & 71 & 80 & 0.102 \\
\hline
\end{tabular}

$\mathrm{TE}=$ Total Energy

The findings of our study suggest that higher consumption of FFs was significantly associated with a lower level of inadequacy for vitamin $\mathrm{D}$ and iron. These findings also show that higher consumption of FFs was significantly associated with greater compliance with dietary recommendations for total fat, saturated fat and carbohydrate.

This project was funded by the Irish Department of Agriculture, Food and the Marine under the Food for Health Research Initiative $2007-2012$.

1. Food Standards Agency (2002) McCance and Widdowson's The Composition of Foods: Summary Edition (6th Edition) Cambridge: Royal Society of Chemistry.

2. Black LJ, Ireland J, Møller A et al. (2011) J Food Comp Anal 24, 1017-23.

3. Schofield WN (1985) Hum Nutr Clin Nutr 39 Suppl 1, 5-41.

4. Torun B, Davies PSW, Livingstone MBE et al. (1996) Eur J Clin Nutr 50, S37-S81.

5. Department of Health (1991) Dietary Reference Values for Food Energy and Nutrients for the United Kingdom. Reports on Public Health and Medical Subjects no. 41. London: H.M.S.O.

6. Institute of Medicine (2011) Dietary Reference Intakes for Calcium and Vitamin D. Washington, DC: The National Academies Press.

7. EFSA Panel on Dietetic Products, Nutrition and Allergies (NDA) (2010) EFSA Journal 8(3):1461.

8. EFSA Panel on Dietetic Products, Nutrition and Allergies (NDA) (2010) EFSA Journal 8(3):1462. 